\title{
LA FUNCIÓN DEL RECONOCIMIENTO Y LA AUTODETERMINACIÓN EN LOS PRINCIPIOS DEL DERECHO INTERNACIONAL HUMANITARIO CONSUETUDINARIO DE MEXIHKO-TENOCHTITLAN
}

\author{
JosÉ Luís GARCía EsPíndoLA ${ }^{1}$
}

RESUMEN: Este artículo es una síntesis dialéctica entre la guerra florida del México precuahtémico y el Derecho Internacional Humanitario, a través del hilo conductor de los usos costumbres, en tanto que son fuente de derecho consuetudinario, lo que, incluye categorías filosóficas, tales como el reconocimiento y la autodeterminación. Se analizan los procesos de juridificación internacional en materia humanitaria durante el ritual de la guerra florida, dicho estudio se hace a partir de la óptica de los principios de precaución de ataque y de distinción, así como el trato a prisioneros de guerra contenidos en los Convenios de Ginebra y sus Protocolos adicionales, para dar cuenta de una Confederación política de naciones aliadas. Así, se supera la noción imperial aztekah, que ha quedado obsoleta ante la hermenéutica que guía la lengua nahua.

Palabras Clave: Derecho Internacional Humanitario, autodeterminación, reconocimiento, leyes de guerra mexihka-tenochka.

ABSTRACT: This paper, is a dialectical synthesis about the ritual war in the ancient Mexico and the International Humanitarian Law, throw about the custom purposes as sources of customary law. It includes philosophical categories, as recognition and selfdetermination. The analysis turns around the procedure in the international legislation, at humanitarian matter during the ritual war, from the principle of distinction, and the principle of human treatment, including the treatment for prisoners of war, cataloged in the Geneva Conventions and later additions, only for give a testimony about this Confederation composed by allied nations. In this context the Aztec empire has been overcome, it became obsolete against this hermeneutic study, guided by the nahua language.

1 Maestro en Política Criminal por la UNAM FES, Acatlán. Programa de Apoyo a Proyectos de Investigación e Innovación Tecnológica: IN303211-3. 
KEY WORDS: International Humanitarian Law, self-determination, recognition, Mexica-techocha warfare law.

SUMARIO: I. Introducción; II. La autodeterminación y el reconocimiento, para una arqueología de la violencia en la guerra de las sociedades primitivas; III. La guerra ritual y la filosofía del Derecho Consuetudinario mexihka-tenochka; IV. El Derecho Internacional Humanitario: los Convenios de Ginebra y sus Protocolos Adicionales; v. El Derecho Internacional Humanitario Consuetudinario en el México precuahtémico; vi. Conclusiones.

\section{In kexkixkauh manitzin Zemanahuak, aik polihuiz, in itenyo, in itahuaka in Mexihko-Tenochtitlan.}

Cimimailpain

\section{INTRODUCCIÓN}

7 a antigua ciudad de Mexihko-Tenochtitlan, ${ }^{2}$ fue en su etapa de esplendor, una de las urbes mejor logradas de su época, su composición política, jurídica, social y cultural, son elementos que pertenecían a una misma constelación de ordenamientos regidos por la fuerza de la costumbre. En el proyecto fundacional mexihka tenochka, es posible observar una tendencia de aglu-

2 En este texto se usará la variante del náhuatl que ha rescatado la escritura de la sociedad cultural de la Conformidad Ollinkan, en la cual la 'h' se pronuncia como 'j' (excepto cuando aparece antes de la 'u', donde se conserva muda) mientras que la 'c' es sustituida por la 'k', debido a que el sonido es más fuerte. La asesoría lingüística para la traducción, la interpretación y la composición gramatical, está dentro de la línea de la etnia nahuahablante de Santa Ana Tlacotenco, en la delegación de Milpa Alta al sur de la actual Ciudad de México. Vid, Galicia, Oswaldo, Galicia, Roque (et. al) Totlahtul yultot, México, Secretaría de Desarrollo Rural y Equidad para las Comunidades, Secretaría de Gobierno del Distrito Federal, 2008. En este sentido esta postura de variante náhuatl, es en sentido dialéctico, la disposición de elementos de dos variables diversas de la lengua, para acceder a los registros genéticos de este lenguaje materno en una perspectiva sintética, que sirva para hacer una arqueología lingüística acerca de la etnia que fundó Mexihko-Tenochtitlan. Es preciso aclarar que, como en el idioma náhuatl, todas las palabras son graves, es decir, que el acento cae en la penúltima sílaba, se respetará su pronunciación general al no acentuar ninguna de las palabras en esta lengua materna contenida dentro de este documento. 
tinamiento de las culturas que les antecedieron, tales como Teotihuakan y la tollan de los toltecas (la legendaria Tula, Hidalgo), en donde los aztekah (aztecas; la 'h' al final se usa para pluralizar), se asentaron años antes de la fundación de su ciudad. La influencia de la mixteca en el arte pictórico y escultórico de los mexihkah-tenochkah, es fácilmente perceptible, mientras que la herencia arquitectónica del Templo Mayor de Mexihko, es una tendencia chichimeka de Tenayokan (hoy Tenayuca, Estado de México). Estos elementos apuntan a una cultura incluyente, fundamentada en principios humanitarios, que en este artículo se desentrañan de los registros lingüísticos, jurídicos y políticos, con el objetivo de reinterpretar la cultura nahua, desde una arqueología de la violencia, es decir, un método para estudiar la antropología política nahua en las relaciones de poder con las otras culturas originarias, para así desarrollar una filosofía del derecho, fundamentada en la observación de la juridificación de relaciones internacionales de los aliados: Mexihko, Texkoko y Tlakopan, analizadas desde las categorías de la autodeterminación en Kant y el reconocimiento en Hegel.

Esto para desentrañar la falacia del "imperio azteca" que se exhibe en el nulo desarrollo tecnológico-militar de la cultura nahua, que en 1500 años (desde Teotihuakan hasta el auge de Tenochtitlan) los ejércitos utilizaron siempre las mismas armas rupestres. El Estado tolteka desarrollaba constantemente tecnologías urbanas, de ingeniería hidrodinámica, de agricultura y de observación astronómica, pero ¿por qué no fue capaz de desarrollar armas más sofisticadas a lo largo de 15 siglos? Nigel Davies sostiene que en Tenochtitlan no existía un ejército regular permanente, "no se encontraban permanentemente armados". ${ }^{3}$ Esto es explicable, dicen los nahuas, porque en las guerras rituales, las leyes prohibían matar al enemigo, pues éste sólo debía ser capturado y tomado prisionero, el 'ser' guerrero, no era sinónimo de asesino, porque lo importante era el conocimiento y la transformación de 'sí mismo'. Así se puede

${ }^{3}$ Davies, Nigel, El imperio azteca, México, Ed. Alianza, 1997, p. 206. 
presuponer que en México, antes de Kuauhtemok, había toda una instrumentación jurídica basada en principios consuetudinarios, de lo que hoy se conoce como Derecho Internacional Humanitario (DIH), en torno a la protección para los prisioneros y a las víctimas de guerra.

El primer apartado es un marco epistemológico fundamentado en el racionalismo de Kant y en el idealismo alemán, de cuna hegeliana. Así, el aparato teórico conceptual, es guiado por Pierre Clastres y su arqueología de la violencia, que básicamente es una antítesis del pensamiento de Hobbes acerca del Estado moderno conservado en el uso de la violencia legítima, ya que los pueblos primitivos no vivían un estado de guerra total de todos contra todos, pues también existieron elementos de intercambio entre las tribus primitivas, lo que permite distinguir alianzas tribales y no un estado total de guerra.

En el segundo segmento, se hablará de la guerra ritual, 'la guerra florida' (xochiyaoyotl), para rastrear el vínculo entre la guerra y la política en el auge de la Triple Alianza, para hallar su relación con el derecho consuetudinario precuauhtémico. En esta perspectiva se analizará el pensamiento político-militar de Nezahualkoyotl contenido en su obra poética, para encontrar los vestigios filosóficos acerca del 'ser' guerrero, una ontología de la guerra ritual, que está íntimamente ligada con la política internacional de los aliados, en términos de los procesos de juridificación durante el auge del triunvirato (mexihka-akolhua-tepaneka), expuestos en las leyes de Nezahualkoyotl que impulsaron el desarrollo de su civilización.

El tercer apartado es una exposición de los elementos que componen al Derecho Internacional Humanitario (DIH), desde la instrumentación de los Convenios de Ginebra de 1949, así como sus protocolos adicionales de 1977 y 2001 , en donde es importante analizar algunos principios de DIH, acerca de los cuales - por motivos de delimitación-, sólo se les dará seguimiento a dos: i) el principio de distinción, que pretende hacer la diferencia entre civiles y militares, y ii) el principio de precaución de ataque, que impide la agresión por 
sorpresa. Importante es, para este estudio, la Cláusula de Martens, acerca de que una norma consuetudinaria tiene un estatus normativo. Así, el tratamiento a prisioneros de guerra establecido por el DIH, es de particular importancia para la lógica jurídico-política de este análisis.

El último capítulo es el planteamiento de una síntesis dialéctica entre: i) la juridificación internacional, fundada en una comunidad trasnacional implementada por los aliados entre el siglo XV y el XVI en el México central y ii) los principios del DIH moderno, como una expresión de civilización, para sintetizar iii) los principios del DIH consuetudinario en el México precuauhtémico, como una propuesta de autoidentidad jurídica para un Estado mexicano contemporáneo, que es acusado por su propio pueblo de ser incapaz de brindar seguridad, ni pública ni subjetiva (en función de los derechos fundamentales) al pueblo que hoy habita el Anahuak.

\section{LOS PRINCIPIOS FILOSÓFICOS DE LA AUTODETERMINACIÓN Y EL RECONOCIMIENTO, PARA UNA ARQUEOLOGía DE LA VIOLENCIA EN EL ESTUDIO DE LA GUERRA EN LAS SOCIEDADES PRIMITIVAS}

Este apartado es un marco epistemológico en materia de filosofía del derecho desde la guía de Kant y de Hegel, en torno al estudio de la antropología política, entendida como el estudio de las relaciones de poder entre diferentes culturas, a partir de los elementos políticos y militares que derivan en procesos de fundación del derecho y su penetración, en espacios donde antes no existía legislación alguna, dicho proceso es la juridificación, que es diferente del de legalización, porque en su núcleo conserva un planteamiento filosófico (al cual se refiere esta arqueología de la violencia), fundamentado en categorías, tales como i) la autodeterminación y ii) el reconocimiento. 
1. La autodeterminación y La JuRidificación en LA PaZ PERPETUA DE KANT

En la filosofía de Kant, la categoría de libertad vinculada con la voluntad, fundidas ambas con la autodeterminación de la filosofía teórica, se distingue de la práctica, al pretender que el principio de autonomía puede ser compatible con el exterior, a partir de una teleología universal basada en acciones conciliadas del libre arbitrio que busca un fin, es en 'sí mismo' una máxima universal. El filósofo de Königsberg, parte de la doctrina de la autodeterminación del sujeto, que se concilia con la autodeterminación de otro sujeto, a partir de los fines universales fundamentales para la filosofia trascendental, que nacen desde la esencia racional interna hacia el orden jurídico externo.

[...]El proyecto jurídico de Kant se basa en la reproducción del orden jurídico interno del Estado a nivel internacional; sin embargo, el carácter de la Constitución internacional no queda resuelto, debido a que Kant propone diferentes modelos de Constitución. De manera opcional existe el modelo del Estado mundial, el modelo de la asociación libre de Estados y la República de los pueblos libremente asociados. La idea originalmente kantiana de crear un sistema mundial de Estados confederados o asociados con base en una legislación universal subyace todavía a los experimentos del siglo XX de formar instituciones con carácter de naciones unidas basadas en una juridificación trasnacional. ${ }^{4}$

En la metafisica de las costumbres, se deduce la juridificación como un mecanismo de secularización, de purificación del estado de guerra de todos contra todos (del que Hobbes ya había hablado), y que para Kant, se repitió en la revolución francesa, lo que identificó como el

4 Müller, Klaus, "Del ius publicum europeaum, a la gobernabilidad global. Estrategias bases y fundamentos de la juridificación" en Becerra, Manuel, La juridificación de las relaciones internacionales, México, UNAM, Instituto de Investigaciones Jurídicas, 2008. pp. 24-25. 
derecho natural, "Que el estado de naturaleza de los pueblos, igual que el de los hombres individuales, es del estado del que se debe salir para entrar en un estado legal". ${ }^{5}$ En La paz perpetua escribió

El estado de paz entre los hombres que viven juntos no es un estado de naturaleza (status naturalis) que es más bien un estado de guerra $[\ldots]$ en el que si bien las hostilidades no se han declarado, si existe una constante amenaza. El estado de paz debe, por tanto, ser instaurado. ${ }^{6}$

El estado de naturaleza de los pueblos al igual que el de los hombres individuales $[\ldots]$ es únicamente provisional, y sólo en asociación universal de estados (análoga a aquella que por la que el pueblo se convierte en Estado) puede valer perentoriamente y convertirse en un verdadero estado de paz. ${ }^{7}$

2. LA DOCTRINA DEL RECONOCIMIENTO Y LA AUTODETERMINACIÓN EN LA FILOSOFÍA DE HEgEL

A finales del siglo XVIII y comienzos del siglo XIX, salieron a la luz importantes escritos del llamado idealismo alemán, influido por los colapsos, convulsiones y transformaciones que habían traído consigo la Revolución francesa y las guerras napoleónicas. El idealismo establece un principio de espiritualidad como inspiración de la normatividad,

Resumiendo la concepción filosófica hegeliana, la fenomenología del espíritu revela la sucesión progresiva de diferentes manifestaciones de la conciencia (subjetiva) que consiste en el pensamiento del objeto, conduce a la autoconciencia como fundamento y culmina finalmente en el saber absoluto, entendido como unidad cohesiva entre subjetividad y objetividad. Sin embargo el saber absoluto es la manifestación del espíritu como autoconciencia, que revela en el

5 Kant, Immanuel, La metafisica de las costumbres, Madrid, Tecnos, 1999, p. 14.

${ }^{6}$ Kant, Immanuel, La paz perpetua, Madrid, Tecnos, 1989, p.14.

7 La metafisica de las costumbres, Op. Cit., p.190. 
arte, la religión y la filosofía, una esfera diferente al espíritu objetivo, este entendido como el mundo de las instituciones históricas. ${ }^{8}$

En esta tesitura, la libertad es una especulación antropológica que se opone a la maquinización de la vida pública representada-dominada por un Estado que, fundado y conservado en la violencia, oprime al individuo, lo hace el esclavo de un amo que lo domina, ${ }^{9}$ lo cosifica, lo hace una extensión de su deseo, así el conflicto se presenta como un elemento decisivo en la configuración de la libertad, "el conflicto entendido como un proceso de reconocimiento entre partes". ${ }^{\circ}$ Dicho reconocimiento entre sujetos conduce a la intersubjetividad, lo que

[...]requiere un modelo de organización jurídica que sostiene finalmente la libertad de cada uno. Por eso, Hegel sostiene la relación entre personalidad, reciprocidad y derecho, afirmando que la personalidad encierra en general, la capacidad jurídica, constituyendo así el concepto y la base del derecho. ${ }^{11}$

El idealismo alemán surgió como una reflexión ante el despliegue de violencia y de terror que se había vivido recientemente en Europa y Hegel se daba cuenta de que la historia se construía en escenarios de conflicto como consecuencia de la realización histórica. En este sentido, la conciencia de la humanidad se desarrolla progresivamente con la conciencia de libertad, pero se revela también como un altar de sacrificios, es decir, la historia revela la universalidad de la conflictividad que desemboca en borbotones de sangre sin tomar

8 Müller, Klaus, "la filosofía política del reconocimiento, el derecho y el uso de la violencia. Una interpretación de la filosofía hegeliana” en Fernández, Jorge, (coord.) Disertaciones de filosofia del derecho, México, UNAM, Posgrado Fes Acatlán, 2013, p.159.

9 Hegel trata la dialéctica del Amo y el esclavo, en la Fenomenología del espiritu, Vid., G. W. H. Hegel, La fenomenología del espíritu, México, FCE, 1966, pp. 117-119.

10 Müller, Klaus, Op., Cit.,. p.161.

11 Idem. 
en cuenta la felicidad de individuos y pueblos. ${ }^{12}$ La historia abre el telón de los escenarios más cruentos de conflicto, un "matadero en el que se han sacrificado la felicidad de los pueblos, la sabiduría de los Estados y la virtud de los individuos". ${ }^{13}$

En este sentido el idealismo construyó una teoría del reconocimiento como facultad que tienen las personas para establecer relaciones de autodeterminación, por lo tanto, en las relaciones interpersonales, el respeto se observa empíricamente como una necesidad, de la superación de la resistencia del individuo a individualizarse, en la insociable sociabilidad del ser humano, el antagonismo se entiende como un medio del que se sirve la naturaleza para lograr un desarrollo del hombre en todas sus disposiciones sociales. Adoptando un enfoque teleológico, Kant afirma que existe un progreso en la historia, pero señala también que la integración en la sociedad no se puede tomar como una garantía, dado que el desarrollo progresivo acontece sobre la espalda de los ciudadanos. ${ }^{14}$ Con lo que respecta a la transición del estado natural, al estado civil instaurado, "el contexto genealógico incluye la concepción del antagonismo que subyace, con modificaciones, a la concepción filosófica de Hegel, concentrada en la lucha por el reconocimiento, que sustituye la figura del contrato (social)". ${ }^{15}$ Es la expresión del concilio entre los arbitrios libres, de los individuos autodeterminados por la voluntad, que se dejan guiar por la universalidad de la esencia racional.

3. La antropología política en la Arqueología de la violencia de Pierre Clastres

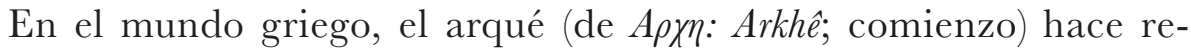
ferencia al origen, y es la raíz etimológica de palabras como ar-

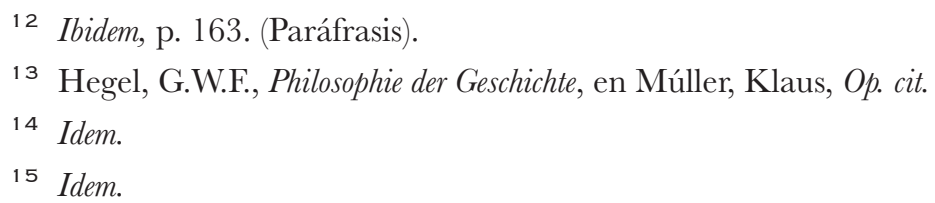


queología y arquetipo. Así, el interés de este artículo atiende a una arqueología de la violencia expuesta en los argumentos de la antropología política, en torno a: i) las relaciones bélicas que surgen por las disputas de poder, para fundar el monopolio del uso de la fuerza legítima y ii) en los conflictos entre el poder ya monopolizado, que sofoca represivamente a las diversas expresiones jurídico-políticas que no corresponden a la lógica de dominio del ente estatal. En la Arqueología de la violencia: La guerra en las sociedades primitivas, Pierre Clastres expone una antítesis del pensamiento Hobbesiano acerca de la guerra total entre los pueblos autóctonos, que se desarrollaron en una etapa pre-estatal y que a partir del surgimiento del Estado moderno, éste ha pretendido aniquilar las disputas primitivas a partir del uso necesario del monopolio de la violencia legítima, en manos de una potestad soberana que asegura con éxito, además, el monopolio de los medios de recaudación impositiva y de la producción del discurso jurídico como expresión legítima del poder.

En esta óptica la arqueología de la violencia es un estudio de antropología política, acerca de la barbarie en su forma más brutal: en la guerra misma, en el derrame de sangre que borra el pasado y construye discursos político-militares, para fundar el derecho que se conservará en la propia violencia. Así, es preciso señalar que en la antropología política de Clastres, las sociedades primitivas, lejos de ser partícipes de una guerra total de todos contra todos, eran sociedades contrarias a la violencia, por lo que resulta imposible concordar los vestigios de las alianzas entre los pueblos originarios (además del comprobado comercio entre ellos), con el argumento de un barbárico estado primitivo de guerra total. El 'ser social' necesita del intercambio y la guerra lo impide, guerra y alianza están en dos hemisferios opuestos.

"La guerra es el modo de existencia privilegiado de la sociedad primitiva, por cuanto se divide en unidades sociopolíticas iguales, 
libres e independientes". ${ }^{16}$ La sociedad primitiva no puede ser de lo Uno, su universalidad guerrera corresponde a la emancipación de una fuerza centrífuga que los impulsa a la migración, a dispersarse, no a reunirse, su tendencia negativa a la unificación, es un rechazo a la hegemonía y la homogenización del discurso del Estado que se conserva en el monopolio de la fuerza, "la comunidad primitiva quiere permanecer bajo la divisa de su propia ley (autonomía, independencia política)". ${ }^{17}$ Rechazar al Estado es rechazar la imposición de la norma externa, equivale a no aceptar la sumisión a la ley escrita, a la alienación de su 'ser' guerrero, que pretende que la guerra es una relación de verdad entre las comunidades. "A mayor guerra, menor unificación, y el mejor enemigo del Estado es la guerra. La sociedad primitiva es una sociedad contra el Estado, por cuanto es sociedad para la guerra". ${ }^{18}$

III. LA GUERRA RITUAL Y LA FILOSOFÍA DEL DERECHO CONSUETUdinARIO MEXIHKA-TENOCHKA

Desde hace miles de años, el territorio que hoy se conoce como México, ha albergado a un amplio abanico de naciones y tribus, que se desarrollaron antes de la llegada de los peninsulares en el siglo XVI al territorio de Anahuak (nombre originario que daban los nahuah a la extensión que hoy comprende desde Alaska - castellanización de axan, que significa "desde" —aquí [Anahuak]- hasta Nicaragua -nican, que significa "hasta" —aquí [Anahuak]). En ese gran territorio se desarrollaron vastas culturas, surgieron poderosas naciones y nacieron sabias civilizaciones, a lo largo de más de 15,000 años. Por tal motivo aquí sólo se estudiará a la cultura mexihka-tenochca entre 1325 y 1521 , de acuerdo con las siguientes tres justificaciones:

${ }^{16}$ Clastres, Pierre, Arqueología de la violencia: la guerra en las sociedades primitivas, Argentina, FCE, 2004, p. 73.

17 Ibidem, p. 76.

18 Ibidem, p. 77. 
1) Los mexihkah-tenochkah fueron el último eslabón de un linaje nahua de sabios toltekah que se había originado en Teotihuakan, había fundado Tula y finalmente radicó en Mexihko-Tenochtitlan, por lo que estudiar a los mexihkah, no solo es explorar las raíces culturales de México, sino que es el rastreo de una tradición jurídico política con más de dos mil años de antigüedad.

2) El nombre de Mexihko es precisamente de origen nahua y le fue otorgado por los mexihkah, después de más de 260 años de buscar el Acontecimiento: cuando los aztekah ${ }^{19}$ hallaron la señal dada por Huitzilopochtli, en la que un águila posada en un nopal designaría el lugar en donde construir su ciudad (hoy esa águila vive mitológicamente y legítimamente en el escudo nacional).

3) Al sur de la actual Ciudad de México se encuentra la delegación de Milpa Alta, en donde habitan comunidades originarias que aún conservan la lengua náhuatl y practican los usos y costumbres de sus ancestros mexihkah, tal es el caso de Santa Ana Tlacotenco, que hasta los años 40's, aún se conservaba monolingüe sin ninguna influencia lingüística castellana. Esta determinación de obtener la asesoría del grupo étnico nahuahablante, obedece a la necesidad de hacer interpretaciones fieles a la cultura nahua.

1. La política internacional de la Triple Alianza

Los nahuahablantes de Santa Ana Tlacotenco, no respaldan la idea de que Mexihko-Tenochtitlan fuera la capital imperial azteka, por el contrario aseguran que hasta antes de la llegada de los españoles, existía una confederación compuesta por varias naciones, "no hay una palabra en nahuatl para decir imperio" dicen los tlacotencas contemporaneos, pero si hubo una Huey tlahtokayotl ikniuhyotl,

19 Los aztecas fueron los migrantes, pero cuando llegaron a México entonces adoptaron el nombre de mexihkah. 
la Gran fraternidad de la palabra (huey: gran; tlahtocayotl; tlahto-lli: palabra; yotl: sufijo sustantivizador; ikniuyotl; ikniuhtli: hermano; yotl: sufijo sustantivizador), reconocida como la gran Confederación de Anahuak, es la formalización jurídico-política del reconocimiento y la autodeterminación, manifiesta en la alianza entre tres federaciones, (Tenochitlan, Texkoko y Tlakopan), a la que se conoce también como la Triple Alianza, que era tanto de jure como de facto, el eje rector de gobierno y de justicia de la Confederación de Anáhuac.

Formaron una auténtica región o icniuyotl (grupo de amistad). Un grupo de calpultin icniuhtli (amigos, hermanos) rurales o urbanos, se federaban como señoríos regionales a su vez autónomos y autárquicos, teniendo al frente de ellos una asamblea de representantes de los calpultin llamada tecuhnechicolli, junta de señores, presidida por un cihuacoatl, administrador y un altepetl, también llamado tlahtoani, que era el ejecutor. Su organización, aunque similar a la del calpulli, tenía mayor incremento en cuanto al comercio, la industria, la educación, la milicia, la ciencia y el arte. ${ }^{20}$

Los mexihkah no eran un pueblo primitivo de bárbaros y salvajes, como ha hecho creer la interpretación univocista castellana:

Los mexicas no ocupaban los territorios, no imponían lengua, ni religión, ni gobierno a los vencidos; no eran un imperio. Los españoles que venían de un imperio, en el que reinaba el emperador Carlos $\mathrm{V}$ y que abarcaba media Europa, pensaban que el sistema de gobierno de los mexicas necesariamente tenía que ser imperial, pero estaban equivocados, ellos que si eran imperialistas ocuparon nuestros territorios e impusieron un gobierno, religión, lengua y cultura. [...] No existía un imperio sino una federación y al frente no había un emperador sino un consejo supremo. El máximo órgano de poder de la federación era el tlahtocan. En el caso de la Confederación del Anahuac, conformada por Tenochtitlan, Texcoco y [...] Tlacopan,

20 El kalpulli (en náhuatl, la doble 'll' se lee como una sola 'l' más larga) era la unidad básica de organización jurídica, política y militar de Tenochtitlan. Vid, Romerovargas, Iturbide, Los Gobiernos Socialistas de Anahuac, México, Sociedad Cultural In Tlilli in Tlapalli, 2000. p. 13. 
cada una de estas tribus tenía su propio tlahtocan, su administrador o cihuacoatl y su ejecutor o tlahtoani. ${ }^{21}$

Al respecto Eulalia Guzmán apunta que:

Ningún pueblo se veía superior a otro por pertenecer a cierto linaje.

La prueba más clara se ve en las peregrinaciones, cuando se asentaban en un pueblo, inmediatamente contraían matrimonio y los señores procuraban que sus hijas y los hijos de los principales se casaran con los que venían. [...] Así que no existían prejuicios raciales, los prejuicios raciales los trajeron los europeos. Así, se afianzaba más el sentido de comunidad y esto hacía que el pueblo recién llegado, inmediatamente ocupara la misma categoría que los que existían aunque vinieran de lejanas tierras o de otro grupo lingüístico. ${ }^{22}$

2. LA JURIDIFICACIÓN DE LAS RELACIONES INTERNACIONALES DE ANAHUAK

La clasificación del derecho consuetudinario, basado en las costumbres mexihkah-toltekah, la hace Romerovargas Iturbide, quien escribió profundamente acerca de la juridificación mexihka-tenochka:

Las principales fuentes del derecho autóctono fueron: la jurisprudencia, los precedentes de los tribunales, la costumbre, las instituciones territoriales y del Estado, las alianzas, los pactos colectivos y la actividad estatal. [...] Todo en la vida de estos pueblos, se regía armoniosamente por la costumbre, que se amolda espontáneamente a las necesidades humanas, y era considerada inviolable, porque responde siempre al interés concreto y general de la colectividad. [...] Teniendo las costumbres un carácter esencialmente jurídico, toda educación consistía materialmente en una escuela práctica del derecho, que disciplinaba al hombre en el ejercicio de las nor-

21 Moctezuma, Pablo, Moctezuma y el Anahuac, México, Noriega, 2000. p.34.

22 Guzmán, Eulalia, Una visión crítica de la historia de la conquista de México-Tenochtitlan, México, UNAM, Instituto de investigaciones Antropológicas, 1989, p. 42. 
mas jurídicas y a la sociedad en el desarrollo práctico de la ciencia del derecho, para realizar el ideal jurídico de la comunidad y del Estado. ${ }^{23}$

La concepción política de los aliados, estaba dada en función del reconocimiento y la autodeterminación,

La igualdad relativa de los hombres entre sí, sometidos a una ley flexible sujeta al árbitro judicial, lo que con firmeza, en caso de conflicto, determinaba la justicia en lo concreto, mediante la sentencia, considerando que a mayor grado jerárquico en la sociedad, mayor, la responsabilidad y mayor rigor en la aplicación del derecho. ${ }^{24}$

En la igualdad relativa de los hombres entre sí, está puesta la categoría filosófica del reconocimiento, mayor mientras que la autodeterminación queda de manifiesta, en que

[...] existían leyes que no eran aceptadas por todas las naciones incorporadas, dando margen a una variedad considerable de leyes y costumbres. Los mexicas no obligaban a los pueblos anexados a hablar su lengua, ni a adoptar sus creencias particulares, tampoco los obligaban a aplicar todas sus leyes, por lo que florecían las instituciones y brillaba con pujanza la libertad junto con el derecho. ${ }^{25}$

El Códice Mendocino menciona que 38 naciones regionales a modo de provincias y las tres cabeceras con sus respectivas naciones formaban la Confederación de Anahuak.

El gobierno de los tres Estados no era el de una simple confederación sino el de una verdadera federación con funciones propias correspondientes a cada una de las cabeceras. A Tenochtitlan correspondía la ejecución militar en todo el territorio, la dirección del comercio y correos, las grandes celebraciones de liturgia oficial y en cuanto al gobierno solo el de su propio señorío.

23 Romerovargas, Iturbide, Organización política de los pueblos de Anahuac, México, Lucerna, 1956, p. 246.

24 Op. Cit, Los gobiernos socialistas de Anahuac, p. 70.

25 Ibidem, p. 69. 
[...]A Texcoco tocaba la ejecución de obras públicas en todo el territorio: caminos, presas, acueductos, albarradas, edificios; llevar el archivo y registro de las genealogías; convocar a juntas de sabios, generalmente en Teotihuacan, formular el derecho común de toda la confederación; impartir justicia en casos complicados y en los conflictos dinásticos de los distintos señoríos.

[...]A Tlacopan incumbía la ejecución de monumentos, obras de arte, joyas e indumentaria y la organización de trabajadores al servicio de la federación. Además cada una de las regiones cooperaba con lo que fuera de su propia especialidad a solicitud de la federación. ${ }^{26}$

El engranaje de las relaciones internacionales de Anahuak entre el siglo XV y el XVI, está fundado en el reconocimiento de las diferencias, en las ventajas competitivas y en la autodeterminación de los pueblos, que regidos por la costumbre, dieron paso a procesos de juridificación, como lo son las 80 leyes de Nezahualkoyotl. Dichas normas son la culminación de una constelación de juristas texkokanos entre los que se encuentran: a) Nopaltzin, quien se preocupó por legislar en favor del entorno natural, so pena de muerte a quien talara o quemara los campos, b) Tlotzin, quien dictó leyes para su pueblo en materia de asentamientos humanos y agricultura, pues dicha legislación promueve el sedentarismo, la siembra y con esto, el fin de las migraciones pre-estatales. c) Kinatzin, refuerza el trabajo iniciado por su antecesor, para estimular el desarrollo económico y asegurar la vida de las nuevas ciudades. Y finalmente d) Nezahualkoyotl, quien dictó con eficiente técnica jurídica las leyes que regirían en la Confederación de Anahuak. ${ }^{27}$

La juridificación de las relaciones internacionales, realizada por Nezahualkoyotl, contempla un catálogo de cuatro materias principales: a) Causas civiles y criminales, b) Música y ciencias, c) guerra

26 Ibidem, pp. 23-24.

27 Salcedo, Antonio, "El universo sociojurídico de los culhuas o antiguos texcocanos", en Alegatos, Num. 76, México, septiembre-diciembre de 2010, p. 843. (Paráfrasis). 
y d) hacienda, ${ }^{28}$ de las cuales, este artículo únicamente analizará la legislación internacional en materia de derecho humanitario, es decir la juridificación en materia militar. En este sentido, "al consejo de guerra se le encargó vigilar, someter y emplazar a los señoríos, que intentaran impedir el comercio o que pretendieran sublevarse". ${ }^{29}$ Dicha instrumentación internacional implicaba protocolos diplomáticos de declaratorias de guerra y leyes castrenses, que regulaban la conducta de las fuerzas armadas aliadas en combate. Fray fuan de Torquemada, religioso franciscano e historiador español de fines del siglo XVI y principios del siguiente, recoge directamente de boca de los indígenas de México una serie de tradiciones y costumbres. Entre ellas, se puede leer una interesante alusión a la manera en que los indígenas se declaraban y se preparaban para la guerra:

Estando ya determinado y acordado que se hiciese la guerra, tomaban ciertas rodelas y mantas y enviábanlas a los que desafiaban y citaban para la guerra, dándoles aviso de ella y la determinación que tenían para hacerla y las causas con que se movían; porque estuviesen apercibidos y no dijesen que los acometían a traición. ${ }^{30}$

En esta óptica la guerra en México antes del siglo XVI no tuvo un sentido de dominación imperial, lo que da paso a nuevas interpretaciones de esta cultura antigua, que se desmarca de una interpretación imperialista, para acercarse hacia una versión de guerra ritual, que estaba muy bien definida y reglamentada ante los organismos legales y legítimos emanados por un consejo llamado Huey Tlahtocanechicolli y no por un emperador. Las leyes de la guerra ritual pretendían proteger a los civiles, principalmente a las muje-

28 Idem.

29 Ibidem, p. 847.

зо Torquemada, Fr. Juan, Monarquía Indiana, en Dary, Claudia, El Derecho Internacional Humanitario y el Orden Furídico Maya, Guatemala, Facultad Latinoamericana de Ciencias Sociales/Comité Internacional de la Cruz Roja (CICR)-Proyecto Maya, 1997, Cap. II. en: <http://www.icrc.org/Web/spa/sitespa0.nsf/ iwpList359/428DBB50C615BE73C1256DE10060CEG1>. 
res, por lo que se apunta a que en México los antecedentes del DIH tuvieron su origen antes de Cuauhtémoc. ${ }^{31}$

\section{Del orden cósmico a las leyes de guerra en el México PRECUAUHTÉMICO}

Para profundizar en el pensamiento militar mexihka-tenochka es preciso acudir a sus mitos, a las narraciones extraordinarias de la nativa etnia nahua acerca de los orígenes del universo, de la vida y del hombre mismo. Los mitos mexicas tienen su origen en las narraciones de Teotihuakan, que a su vez les fueron heredadas a los toltecas y estos a los migrantes aztekah: Mexi y Tenoch, quienes finalmente fundaron la ciudad de Mexihkco-Tenochtitlan. ${ }^{32}$

La versión de los ancianos nahuahablantes de Milpa Alta, en tanto tradición oral, se expresan en la palabra del anciano Teuctli, quien durante sus prácticas rituales de temazkal narra:

[...] en el inició del universo nahua existió, y aún existe, una pareja primigenia que habita en el Omeyokan, es el corazón del cosmos, desde el principio mismo de la creación quienes tuvieron cuatro hijos, de entre ellos uno nació negro llamado Tezkatlipoka y el otro blanco fue nombrado Ketzalkoatl, así que como hacen los hermanos, comenzaron a pelear entre ellos, de las chispas surgidas de su lucha comenzaron a formarse las estrellas, entre ellas el sol, por eso son los hermanos creadores y formadores del universo, $[\ldots]$

los fundadores de la guerra florida.

31 Para los mexicanistas es lo propio decir antes y después de Cuauhtémoc para marcar la ruptura de dos eras, de la misma forma que los cristianos dicen antes o después de Cristo para distinguir dos bloques históricos.

32 En la cuna de la civilización occidental se contempla a la civilización egipcia, quien heredó sus mitos cosmogónicos a los griegos y estos a su vez a los romanos, así los teotihuacanos heredaron sus mitos a los toltecas de Tula y fueron los mexicas quienes finalmente los reafirmaron en su ideología durante su hegemonía política. 
El códice Chimalpopoca verifica lo que el anciano Teuctli narra, y agrega que la lucha entre el hermano negro y el hermano blanco dio como resultado la formación de cinco eras cosmogónicas o soles. Dicha información puede ser verificada en el segundo círculo del Calendario Azteca o Estela de los Soles, que se encuentra actualmente en la Sala Mexica del Museo Nacional de Antropología de la Ciudad de México.

En esta óptica las narraciones de la etnia nahua hablan de que la guerra es, en 'sí misma', un acto creativo, ya que no basta entender el mito cosmogónico entre Tezkatlipoka y Ketzalkoatl, sino que ese combate creativo, es al mismo tiempo el origen de la guerra ritual, es decir de la guerra florida, que va más allá de una narración extraordinaria, si se entiende desde la realidad nahua en donde los hermanos mencionados son fuerzas antagónicas que prevalecen desde la cosmogénesis, hasta la perpetua resistencia entre los opuestos (entre el negro y el blanco).

El núcleo del pensamiento individual del guerrero es forjado en la guerra como un acto simbólico altamente ritualizado, en el que el guerrero es la superación espiritual del hombre, en la misma lógica en que el hombre es la superación del primate. Por lo que el guerrero nahua es un 'ser' en tanto es guerrero, es decir, en lo que respecta a la superación de 'sí mismo' mediante la guerra florida, entendida como un combate creativo y fundador. En esta lógica el 'ser' se crea a 'sí mismo', es autopoiético, (moyocoyani) se genera y se inventa a través de la lucha entre los contrarios, de la confrontación entre sus opuestos que se desafían durante la experiencia cotidiana, que nace de la vivencia como representación de dos impulsos o fuerzas antagónicas en resistencia, para encontrar la expresión subjetiva durante la guerra ritual, con el fin de realizar una alineación, una síntesis, entre las dos fuerzas opuestas en resistencia. ${ }^{33}$

3з El Tezkatlipoka negro, ha sido asociado con el impulso de muerte y la oscuridad del inconsciente, al mismo tiempo que el blanco Ketzalkoatl representa la experiencia creativa de la vida y la claridad de la consciencia. 
Durante el auge mexihka-tenochka se esculpió un importante monolito, al que Alfonso Caso ${ }^{34}$ reconoció como el Teocalli de la Guerra Sagrada (actualmente se encuentra en la sala mexica del Museo Nacional de Antropología). La guerra sagrada que evoca el monolito es la guerra ritual nahua. Sería exhaustivo hacer un análisis de todos y cada uno de los símbolos del Teocalli, por lo que únicamente se analizará el más grande de todos, el que se encuentra en su parte posterior, en donde está esculpida el águila mítica - posada en el nopal-, que es al mismo tiempo, el Acontecimiento: la señal dada por Huitzilopochtli para la fundación de Mexihko-Tenochtitlan, y de hecho quien inspira la imagen del escudo nacional mexicano, sólo que entre ambos símbolos existe una sustancial diferencia, que el águila en su pico no tiene una serpiente sino un atlachinolli.

Acerca del concepto atlachinolli, Miguel León Portilla lo rescata de los cantos de guerra (yaokuikatl),

[...] en náhuatl el concepto de guerra se expresa muchas veces valiéndose de un difrasismo, es decir la conjunción de dos vocablos de cuya aproximación salta la chispa que ilumina el significado. El difrasismo es aquí el atl, tlachinolli, Agua chamuscada, evocación de dos realidades contrarias, por no decir antagónicas. ${ }^{35}$

La traducción que el nahuahablante Teuctli da al concepto de atlachinolli, es el de agua quemada, que por sí misma es una cosa que no existe, por lo que deberá contener un significado metafórico. El difrasismo del signo que se encuentra en el pico del águila del Teocalli de la Guerra Sagrada, es según la tradición oral de la etnia nahua de Milpa Alta, un concepto de lucha entre opuestos, el atl es el agua, tlachinolli es el fuego, tal como fuerzas elementales antagónicas que asocian, por un lado al frío con la luna y la mujer, y por el otro al calor con el sol y el varón. El concepto nahua del

34 Vid, Caso, Alfonso, El Teocalli de la Guerra Sagrada: descripción y estudio del monolito encontrado en los cimientos del Palacio Nacional, México, SEP, 1927.

35 León-Portilla, Miguel, Poesía náhuatl, México, Ed. Diana, 2006, p. 57. 
atlachinolli evoca el equilibrio, el reconocimiento entre opuestos, ya que, si es cierto que el fuego y el agua son elementos contrarios, es una realidad que cuando la humedad (de la mujer) y el calor (del varón) se fusionan, entonces se crea el caldo de cultivo necesario para la formación de una "nueva" forma de existencia. En una perspectiva ontológica, de la hermenéutica acerca del difrasismo del atlachinolli, el frío simboliza la muerte y el silencio interno, en tanto que el calor es la vida que se expresa en la experiencia creativa.

4. La ontología del guerrero y su muerte al filo de OBSIDIANA

De la muerte en la guerra dicen los cantos nahuah:

[...]que son embriaguez en medio de la llanura. Es encontrar la muerte al filo de obsidiana y, así mismo, es tiempo y espacio donde águilas y jaguares, con toda su fuerza, sacuden a cuanto existe en el mundo. Es, en sí, donde los seres humanos dejan recuerdos de sí mismos, recuerdo que perdurará para siempre en los libros de pinturas. ${ }^{36}$

Si se entiende al 'ser' desde la experiencia óntica de la consciencia durante la guerra ritual, el difrasismo de la muerte del 'ser' deóntico, adquiere una noción de duelo por el corte con el 'deber ser' y la predeterminación ontológica, el filo de obsidiana entiende dos realidades que resultan de dicho corte: la muerte contiene a la vida, tanto como la vida contiene a la muerte, es decir la creatividad contiene al silencio tanto como el silencio contiene a la creatividad. En los poemas del forjador de cantos: el tlahtoani (de tlahtoa: palabra y ni: el que; es sufijo nominalizador), el portador de la palabra Nezahualcoyotl, canta:

\section{Esmeraldas}

turquesas,

son tu greda y tu pluma

36 Idem. 


\author{
ioh por quien todo vive! \\ Se sienten felices \\ los príncipes, \\ con florida muerte a filo de obsidiana, \\ con la muerte en la guerra. ${ }^{37}$
}

Ya en el texto Guerra, sacrificios y significados, ${ }^{38}$ he realizado un estudio hermenéutico acerca de éste poema, escrito durante el auge de la Triple Alianza, cuando el poeta guerrero era el señor de Texkoko, significativo porque refleja la ideología político-militar dominante de la época. El estudio de este fragmento poético, descubrió que la muerte en la guerra estaba ideológicamente insertada en el consejo militar de los aliados, compuesto por guerreros águilas y jaguares. Metaforizada como la muerte al filo de obsidiana, la transformación del guerrero es la muerte ideal, que lleva al espíritu del guerrero encarnado por un colibrí (la fuerza de voluntad) a habitar el Tamoanchan, la casa del sol (la iluminación -la de la consciencia-). ${ }^{39}$

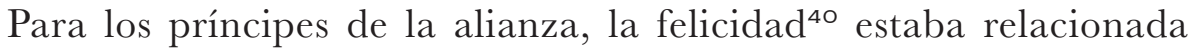
con la muerte en la guerra, al filo de obsidiana, el estudio hermenéutico comprende el corte con la objetivación ontológica del 'ser' cosificado, para alcanzar la subjetivización óntica del 'ser', que da un salto cualitativo de 'ser' humano a 'ser' guerrero (de hombre a

37 Ms. Romances de los señores de la Nueva España f42, trad. Garibay, Poesía náhuatl, t. I, num.60 p. 101.

38 García, José Luís, Guerra, Sacrificios y significados, Yautepec, Morelos, ponencia del 2do congreso nacional de Psique y Cultura: Asociación de Estudios Transdisciplinarios, 2009, disponible en: <http://www.yaollin.com.mx/bibliotecavirtual/>.

39 La analogía de la metáfora de la muerte al filo de obsidiana, es una muerte simbólica equiparable con la filosofía shramánica, específicamente con lo que se conoce como 'nirvana' (del sánscrito: desatar [os nudos de la psique]), que se alcanza cuando el alma encuentra al 'ser' liberado de sufrimientos, una idea muy fecunda en el hinduismo y el budismo.

40 Para Aristóteles la felicidad es el bien supremo del hombre, para él la felicidad está relacionada con el honor, es un regalo de los dioses que es otorgado a los hombres virtuosos. Vid. Aristóteles, Etica Nicomaquea, México, Porrúa, 1992, pp. 5-17. 
superhombre, en la óptica de la filosofía del martillo que Nietzsche planteó en Así habló Zaratustra).

5. La función de Ketzalkoatl en el ritual cósmico y las LEYES DE GUERRA

Los mexihkah-tenochkah heredaron de los toltekah sus conocimientos astronómicos. En todas las ciudades de influencia tolteka (inclusive Chichen Itza), yacen observatorios astronómicos, que en su época de esplendor servían para seguir el camino de los cuerpos celestes, principalmente el Sol (Tonatiuh), la Luna (Meztli) y el planeta Venus (Ketzalkoatl, Tlahuizkaplantekuhtli-Xolotl). Este último tiene un matiz peculiar, ya que pertenece al contexto que aquí interesa: la muerte al filo de obsidiana, que desde el difrasismo nahua es una muerte ritual, en tanto que es guerra florida, es una muerte simbólica.

Para entender la muerte ritual, los nahuah se basan en las cuatro fases que completan la revolución sinódica del planeta Venus, en las que sólo dos de ellas es visible, una durante el amanecer (salida heliacal) y la otra durante el atardecer (puesta heliacal). Es sustancial para este estudio, aclarar que las guerras rituales se realizaban sólo en determinadas posiciones del planeta Venus. ${ }^{41}$ Según parecen indicar algunos glifos, las guerras no ocurrían en cualquier momento, sino en determinadas posiciones del planeta Venus (como el glifo Tlaloc-Venus). ${ }^{42}$ 'Las decisiones acerca de donde y cuando realizar una batalla estuvieron sujetas a los ciclos de Venus y Júpiter. Para

41 Vid. Salido, Roberto, El regreso de Quetzalcoatl, México, Impresiones artísticas, 1977. pp. 21,45-46.

42 El glifo que Claudia Dary identifica como Tlalok-Venus, se encuentra en el Templo de los jaguares de Teotihuakan, de hecho es una representación de Tlahuizkalpantekuhtli, es decir el planeta Venus como estrella de la mañana. Tlahuizkalpantekuhtli es la representación de la transparencia espiritual y de la luminosidad del 'ser' para servir como guía a través de la congruencia entre actos y pensamientos. Vid, Dary, Claudia, El Derecho Internacional Humanitario y el Orden Furídico Maya, Guatemala, Facultad Latinoamericana de Ciencias Sociales/Comité 
Friedel se trató de un tipo de guerra sagrada determinada por las estrellas". 43

En todas ellas [las guerras] Venus participó desde el cielo dando su beneplácito a los vencedores. Las observaciones astronómicas entre los mayas prehispánicos cumplían con un fin específico: conocer si los dioses [las fuerzas naturales, planetarias y estelares] aprobarían o rechazarían las acciones del hombre. Venus, dado su carácter guerrero, aparece como uno de los planetas-dioses más destacados, su reaparición y desaparición en el cielo señalaba muerte y desgracia en la tierra. ${ }^{44}$

El seguimiento de Venus-Ketzalkoatl (para los nahuah) o Kukulkan (para los mayas) tendría que ver con los movimientos de Venus, que en ambas culturas anunciaban el inicio y el fin de las guerras rituales. La concepción de la guerra estaba ligada al cosmos planetario, lo que lleva a pensar que la guerra unía el estrato cosmogónico, con el astronómico, con el psíquico y finalmente con el físico. Nigel Davies ha apuntado: "resulta asombroso que en el caso de estas guerras, en las que nunca estuvo del todo ausente el elemento ritual". ${ }^{45}$ El ritual es el reflejo de un orden, para Mircea Eliade, "es la actualización del mito" que encarna cada tradición, por lo tanto, el rito es en sí una costumbre, que es una de las fuentes del derecho consuetudinario nahua.

Venus estaba íntimamente relacionado con la guerra. Pero los conjuntos iconográficos indican que también Tlaloc tenía un lugar importante en estas ideas. [...]Los momentos que aseguraban el mayor éxito de las operaciones, eran las primeras apariciones de la estrella de la tarde; otras fechas corresponden a los días de la

Internacional dela Cruz Roja(CICR)-Proyecto Maya, 1997, en: < http: / /www.icrc.org/ Web/spa/sitespa0.nsf/iwpList359/428DBB50C615BE73C1256DE10060CEC1>.

43 Idem.

44 Arellano, Alfonso, "Las Guerras Venusinas entre los Mayas" en Arqueología Mexicana, México, No. 47, INAH Enero-Febrero, 2001, p. 38.

45 Davies, Nigel, El imperio azteca, México, Ed. Alianza, 1997, p. 219. 
última visibilidad de la estrella vespertina, de la primera y la última visibilidad de la estrella matutina y a los días cercanos a la máxima elongación o la mayor altura sobre el horizonte.

Iztlacoliuhqui, identificado como el movimiento estacionario y retrogrado del planeta Venus, era considerado grande augurio para guerras. [...]Las batallas sucedían, por varias razones cuando Venus estaba en la parte sur de la bóveda celeste. Sólo los momentos precisos de estos eventos fueron dictados por los criterios astronómicos. ${ }^{46}$

Todo ritual responde a normas, seguidas protocolariamente por quienes participan de la liturgia. En este caso la guerra es el rito que revive el mito cosmogónico, así, la costumbre tenía prohibido matar al enemigo en combate, solamente debía ser capturado y hecho prisionero.

Desde 1975, Floyd Lounsbury y otros lingüistas y epigrafistas basados en las ideas de Yuri Knorosov descubrieron que los glifos no eran ideografías abstractas sino que reproducían el lenguaje hablado (sílabas, verbos, sujetos, predicados, etc). Así, ha podido conocerse que existían verbos que significaban por ejemplo el acto de capturar, lo que ha permitido ir hilando los diferentes acontecimientos guerreros. ${ }^{47}$

"Los indios sencillamente no comprendían el significado de la guerra total del modo en que se libraba en la Europa del siglo XVI. El impulso por capturar, antes que matar, fue siempre un factor que los inhibió". ${ }^{48}$

46 Sprajc Ivan, La estrella de Quetzalcoatl, México, Ed Diana, 1996, pp. 77, 78.

47 Op cit. Dary, Claudia.

48 op cit. Davies Nigel, p.230. En este sentido es probable deducir las causas por las que fueron vencidos los guerreros tenochkah: i) las diferentes concepciones de la guerra, mientras que para los mexihkah era parte de un ritual que implicaba una ideología fundamentada en la cosmogénesis, en el honor que daba paso a las leyes humanitarias durante la guerra ritual, y ii) para los ibéricos representaba un medio para obtener poder, control de territorios y botín de guerra. 
Los combates se reducían al choque de las masas de ambos contendientes que se fraccionaban en combates individuales cuyo mayor interés era capturar vivo al adversario, o sea que la guerra siempre tenía un carácter sagrado aunque no se tratase específicamente de una guerra florida. ${ }^{49}$

Ángel Ma. Garibay menciona algunas leyes que los mexicas debían seguir en la guerra, ${ }^{50}$ bajo pena de muerte para quien cometía alguna de las siguientes faltas: i) Mentira.- cuando los mensajeros alteraban el correo. ii) Traición.- cuando alguien daba noticias a los contrarios. iii) Violación.- aquel que violentaba a una mujer o la cautiva de guerra. iv) Robo.- aquel que quitaba el cautivo a otro.

Estas penas son significativas si se toma en consideración que la tercera protege explícitamente a la mujer y a la prisionera de guerra. La alineación cósmica entre el guerreo y el orden del ritual, es un signo que da a la guerra una perspectiva humanitaria con status de norma consuetudinaria.

IV. EL DERECHO INTERNACIONAL HUMANITARIO CONSUETUDINARIO: Los convenios de Ginebra y SUS PRotocolos adicionales

Con el término de la segunda guerra mundial y la posterior creación de las Naciones Unidas, se dio paso a un nuevo orden que propuso nuevos organismos y normatividades internacionales. En ese marco se formalizó y se reguló la protección de las personas durante un conflicto armado, con el fin de evitar su sufrimiento. En los cuatro Convenios de Ginebra del 12 de agosto de 1949 y los Protocolos adicionales I, II del 8 de junio de 1977 y más recientemente en el III Protocolo adicional del 8 de diciembre de 2005, se compromete a los Estados Miembros a cumplir y difundir los Convenios lo más

49 Canseco, Vincourt, "La Guerra Sagrada”, en Lameiras, José, Déspotas armados, un aspecto de la guerra prehispánica, Zamora, Colegio de Michoacán, 1985, p. 79.

50 Garibay, Angel, Teogonía e historia de los mexicanos, México, Porrúa, 1985. p. 88. 
ampliamente posible, tanto en tiempo de paz como en tiempo de conflicto armado, de forma que dichos instrumentos puedan ser conocidos y cumplidos por las fuerzas armadas y la población civil.

Así, surge formalmente el derecho Internacional Humanitario (DIH) el cual se define, según la Secretaría de Marina de México (SEMAR), como "el conjunto de normas que, en tiempo de guerra, protege a las personas que no participan en las hostilidades o que han dejado de hacerlo. Siendo el principal objetivo limitar o evitar el sufrimiento humano en tiempos de conflicto armado". ${ }^{51}$

1. Los ANTECEDENTES ARCÁICOS DEL DERECHo InTERnacional HuMANITARIO

Ubicar el inicio del DIH puede remontarse al primer código que rigió a una sociedad en la historia de la humanidad, creado por el Rey Hammurabi en el año 1760 a.C., el cual contiene 282 leyes con sus respectivas penas y/o sentencias. Las leyes del Código Hammurabi están inscritas en piedra para que nadie pueda cambiarlas ni alterarlas, ya que están inspiradas en un dialogo entre el rey Hammurabi y Shamash (el "dios Sol” mesopotámico).

Las 282 leyes que establece el Código Hammurabi sirven para regir las relaciones de toda una sociedad, pero la razón por la que ha sido mencionado en este trabajo, es porque las leyes 27 y 28 mencionan el trato a prisioneros de guerra, por lo que entra en el campo de estudio del DIH. En otro sentido los artículos 38 y 39 de dicho código hacen mención de la distinción entre militares y civiles, ya que especifica situaciones en las que soldados y oficiales tienen un trato distinto al recibido por la sociedad civil, con respecto a algunos servicios prestados al rey. Aunque no es un principio de distinción propiamente establecido, es viable tomarlo como antecedente.

51 Disponible en: <http://www.semar.gob.mx/sitio_2/normateca/derechointernacional-humanitario.html $>$. 
En la era moderna una referencia importante del DIH consuetudinario es la cláusula de Martens, por ser parte del derecho de los conflictos armados, desde que apareciera, por primera vez en 1899, en La Haya en lo relativo a las leyes y costumbres de la guerra terrestre, precisamente con respecto al principio de distinción entre civiles y militares. ${ }^{52}$ Ya que esta cláusula es un referente del DIH consuetudinario, es propio hacerle un seguimiento que fundamente el marco jurídico de este apartado. La Corte Internacional de Justicia (CIJ) ha analizado minuciosamente la cláusula de Martens a través del dictamen del juez Shahabuddeen "(párrafos 78 y 84), en la que la Corte determina que la cláusula de Martens es una norma consuetudinaria que tiene, por lo tanto, un estatuto normativo". ${ }^{53}$ El juez Shahabuddeen, ha destacado que la cláusula de Martens no es solo un recuerdo de la existencia de otras normas de derecho internacional que no forman parte de un tratado específico. Para la CIJ dicha cláusula tiene un estatuto normativo por derecho propio y, por lo tanto, funciona independientemente de las demás normas.

El juez Shahabuddeen dice que los principios del derecho internacional a los que se hace referencia en la Cláusula dimanan de una o más de tres fuentes distintas: las costumbres establecidas entre las naciones civilizadas (denominadas "usos establecidos" en el art.

52 "La cláusula se basa en una declaración leída por el profesor von Martens, delegado de Rusia en la Conferencia de la Paz de La Haya de 1899. Martens añadió la declaración después de que los delegados de la Conferencia de la Paz no lograran ponerse de acuerdo sobre la cuestión del estatuto de las personas civiles que portaban armas contra una fuerza ocupante. [...] Aunque, en un principio, la Cláusula fue redactada para resolver este problema, aparecen, luego, distintas versiones - si bien similares - en tratados posteriores por los que se regulan los conflictos armados." Vid. Ticehurst, Rupert, "La cláusula de Martens y el derecho de los conflictos armados" en Revista Internacional de la Cruz Roja, No 140, 1997, pp. 131-141 en: < http://www. icrc.org/web/spa/sitespa0.nsf/html/5TDLCY>.

53 Idem. 
1.2 del Protocolo adicional I), las leyes de la humanidad (denominadas "principios de humanidad" en el art. 1.2) y las exigencias de la conciencia pública (denominadas "dictados de la conciencia pública" en el art. 1.2). Parece que, determinando todo el alcance del derecho de los conflictos armados, la cláusula de Martens permite ir más allá del derecho convencional y de la costumbre para invocar los principios de humanidad y los dictados de la conciencia pública. Esta interpretación cuenta con el apoyo del Comité de Derecho Internacional, que declara "[la cláusula de Martens] estipula que, incluso en los casos no contemplados por acuerdos internacionales específicos, las personas civiles y los beligerantes permanecen bajo la garantía y el régimen de los principios del derecho internacional preconizados por los usos establecidos, los principios de humanidad y los dictados de la conciencia pública". ${ }^{54}$

La cláusula de Martens es importante porque, por la referencia que hace al derecho consuetudinario, señala la importancia de las normas consuetudinarias para la regulación de los conflictos armados. Además, menciona "los principios de humanidad" y "los dictados de la conciencia pública". Es importante comprender el significado de esas expresiones. La expresión "principios de humanidad" es sinónima de "leyes de la humanidad"; en la primera versión de la cláusula de Martens (Preámbulo, II Convenio de La Haya de 1899) se dice "leyes de la humanidad"; para la última versión (Protocolo adicional I) se emplea "principios de humanidad". Los principios de humanidad se interpretan en el sentido de que prohíben los medios y métodos de hacer la guerra que no sean necesarios para obtener una ventaja militar definitiva. Jean Pictet interpreta el concepto de humanidad en el sentido de que "la humanidad exige que se prefiera la captura a la herida, la herida a la muerte, que, en la medida de lo posible, no se ataque a los no combatientes, que se hiera de la manera menos grave - a fin de que el herido pueda ser operado y después curado - y de la manera menos dolorosa, y que la cautividad resulte tan soportable como sea posible". ${ }^{55}$

$$
\begin{array}{ll}
54 & \text { Idem. } \\
& 55 \text { Idem. }
\end{array}
$$


Además de los principios mencionados por la cláusula de Martens, el DIH establece otros principios, de los cuales -por motivos de delimitación-, sólo se les dará seguimiento a dos: i) Principio de distinción, que pretende hacer la diferencia entre civiles y militares ii) Principio de precaución de ataque.

i) Principio de distinción. - La oficina del Alto Comisionado para los Derechos Humanos en Colombia, emitió el 30 de junio de 2003 el comunicado de prensa Sobre la importancia del principio humanitario de distinción en el conflicto armado interno, ${ }^{56}$ del que se retoma lo siguiente:

Uno de los principios fundamentales del derecho internacional humanitario es el de distinción entre quienes participan directa o activamente en las hostilidades y quienes en ellas no tienen esa participación. Aplicar tal principio resulta necesario para determinar las obligaciones y los derechos que corresponden a unos y a otros. La aplicación del principio de distinción obliga, entre otras cosas, a: $1^{a}$ Garantizar a la población civil y a las personas civiles el trato humano y la protección general.

$2^{a}$ Asegurar a quienes se han rendido y a quienes han quedado fuera de combate el trato humano para ellos.

$3^{a}$ Hacer efectivas las garantías previstas por el derecho humanitario para las personas privadas de la libertad por motivos relacionados con el conflicto.

$4^{\text {a }}$ Evitar ataques contra bienes que no son objetivos militares. ${ }^{57}$

ii) Principio de precaución de ataque durante conflicto armado, mencionado en el artículo 57 del capítulo IV referente a las medidas de precaución del Protocolo I Adicional a los Convenios de Ginebra del 12 de agosto de 1949, relativo a la Protección de las Víctimas de los Conflictos Armados Internacionales, del cual se retoma lo siguiente:

56 El comunicado sobre la importancia de los principios humanitarios, se encuentra disponible en: <http://www.hchr.org.co/publico/comunicados/2003/cp0313.pdf>.

57 Idem. 
1. Las operaciones militares se realizarán con un cuidado constante de preservar a la población civil, a las personas civiles y a los bienes de carácter civil.

2. Respecto a los ataques, se tomarán las siguientes precauciones:

a) quienes preparen o decidan un ataque deberán:

i) hacer todo lo que sea factible para verificar que los objetivos que se proyecta atacar no son personas civiles ni bienes de carácter civil, ni gozan de protección especial, sino que se trata de objetivos militares.

ii) tomar todas las precauciones factibles en la elección de los medios y métodos de ataque para evitar o, al menos, reducir todo lo posible el número de muertos y de heridos;

iii) abstenerse de decidir un ataque cuando sea de prever que causará incidentalmente muertos o heridos en la población civil.

b) un ataque será suspendido o anulado si se advierte que el objetivo no es militar o que goza de protección especial, o que es de prever que el ataque causará incidentalmente muertos o heridos entre la población civil.

c) se dará aviso con la debida antelación y por medios eficaces de cualquier ataque que pueda afectar a la población civil, salvo que las circunstancias lo impidan.

\section{ElDerecholnternacional Humanitario Consuetudinario}

En este marco conceptual también se pretende dejar claro el concepto de DIH consuetudinario. El Estatuto de la Corte Internacional de Justicia en su artículo $38^{\circ}$ define el derecho consuetudinario como "una práctica generalmente aceptada como derecho".

Se acepta en general que la existencia de una norma de derecho internacional consuetudinario requiere la presencia de dos elementos, a saber, la práctica estatal (usus) y la creencia de que esa práctica se exige, se prohíbe o se permite, según la índole de la norma, como derecho (opinio juris sive necessitatis). Como la Corte Internacional de Justicia afirmó en el asunto Continental Shelf, "es naturalmente axiomático que la materia del derecho internacional consuetudinario hay que buscarla ante todo en la práctica efectiva y en la opinio juris 
de los Estados". El significado exacto y el contenido de estos dos elementos han sido objeto de muchos escritos eruditos. El modo de proceder seguido en este estudio para determinar si existe una norma de derecho internacional consuetudinario general responde a un planteamiento clásico, expuesto por la Corte Internacional de Justicia en varias causas, en particular en los asuntos North Sea Continental Shelf. ${ }^{58}$

Un último elemento que interesa a este marco es el III Convenio de Ginebra del 12 de Agosto de 1949 relativo al trato debido a los prisioneros de guerra, que deberán ser tratados de acuerdo a las disposiciones ya señaladas por los dispositivos internacionales del DIH.

\section{Derecho internacional humanitario consuetudinario en el Mexico precuahtémico}

Para retomar el hilo conductor humanitario de la Triple Alianza, es pertinente reinterpretar las costumbres guerreras practicadas en México antes de la invasión ibérica. El sentido humanitario de su expresión jurídico-política, puede detectarse a partir de ciertos principios que han sido mencionados en el tercer apartado de este mismo documento. Este artículo demuestra que la guerra en el México precuautémico estaba altamente cargada de leyes humanitarias, esto a partir de los principios que establecen los Convenios de Ginebra tales como: $i$ ) el principio de distinción (entre sociedad civil y el ejército), así como ii) el principio de precaución de ataque, que protege a la sociedad civil en caso de ataque militar a objetivos castrenses dentro de las ciudades y finalmente, iii) el carácter de derecho consuetudinario en tanto costumbre-tradición durante la aplicación de las leyes de guerra.

58 Henckaerts, Jean-Marie, "Estudio sobre el derecho internacional humanitario consuetudinario: una contribución a la comprensión y al respeto del derecho de los conflictos armados", en Internacional review of the Red Cross, No. 857, CICR, marzo de 2005. p. 6. 
i) El Principio de distinción se identifica en la protección especial que se le dio a la mujer que estaba bien tipificada en las leyes de guerra rescatadas por Ángel Garibay.

ii) El principio de precaución de ataque del que da cuenta Fray Juan de Torquemada.

Los elementos que establece el Estatuto de la Corte Internacional de Justicia en su artículo 38, en el cual define al derecho consuetudinario como "una práctica generalmente aceptada como derecho." En el marco de este artículo, se mencionó que Jean-Marie Henckaerts, ha distinguido que el DIH requiere de la presencia de dos variables: a) la práctica estatal (usus) b) y la creencia de que esa práctica se exige, se prohíbe o se permite, según la indole de la norma, como derecho (opinio juris sive necessitatis). Desde esta perspectiva, en la jurídificación internacional de la Triple Alianza, se ven cumplidas ambas variables: i) La práctica estatal (usus) se manifiesta en la juridificación de la guerra ritual de la Confederación de Anahuak, pues las costumbres militares tenían un carácter jurídico, para realizar el ideal político de la comunidad y del Estado. ii) Práctica según la indole de la norma como derecho (opinio juris sive necessitatis). La vida de los pueblos mesoamericanos se desarrolló de acuerdo a la tradición que al ser aceptada como costumbre adquirió en la práctica el status de norma, en tanto que era una conducta ritualizada aceptada como derecho.

\section{vi. Conclusiones}

A partir de las categorías del reconocimiento y la autodeterminación, se han dado los principios filosóficos para estudiar la guerra ritual mexihka-tenochka, entendida como un conjunto de normas y tratados sustentados en la costumbre, ampliamente influenciada por una ontología guerrera. Con el reconocimiento a las lenguas locales y la autodeterminación de las leyes de las naciones confederadas se demostró la falacia del "imperio azteca", para rescatar un sistema de relacio- 
nes internacionales basado en el equilibrio de poder entre las tres potencias de Anahuak: Mexihko, Texkoko y Tlakopan. La ideología política de los aliados, se sostenía por una cosmovisión, en donde la guerra ritual era un espacio de expresión, creativa (de autopoiesis), comprender la muerte en la guerra, la muerte al filo de obsidiana, es penetrar la expresión simbólica del corte con el 'ser deóntico', es la figura del rompimiento con la objetividad del 'deber ser', para iluminar al sujeto, en su perspectiva óntica. El combate florido fue una justa guerrera regida por el honor y normas humanitarias, al mismo tiempo que era un camino, para encontrar la felicidad.

A través de esta arqueología de la violencia - en tanto antropología política-, se obtuvieron resultados relevantes en materia humanitaria, no solamente a partir de la interpretación política de los mitos, sino desde la hermenéutica del linaje lingüístico que emitió la producción poética de los guerreros que forjaron el sistema político internacional de Anahuak entre el siglo XV y el XVI, y a su vez promulgaron su juridificación. Es el caso del poeta guerrero de Texkoko, Nazahualkoyotl, quien se unió a una cadena de juristas que legislaron en favor del desarrollo y la pacificación de su época, a partir del sentido humanitarista, como núcleo político de los procesos de juridificación. La implementación de rituales guerreros de acuerdo a la aparición de Venus en el manto celeste, dan la pauta de un ordenamiento cósmico, inspirado por el equilibrio entre fuerzas antagónicas, con Ketzalkoatl (venus) como marcador del inicio y el fin de las contiendas militares. La constelación de elementos que componen el DIH consuetdinario de los aliados: Tenochtitlan, Texkoko y Tlakopan, es la puesta en marcha de los principios que sustentan la juridificación de la guerra, una muestra de la civilización expuesta en las leyes que permitieron tal desarrollo espiritual humanitario, que les permitió gestar a una de las culturas más importantes que han poblado la tierra, el linaje del camino rojo, del linaje tolteka-chichimeka, auténtica raíz jurídico-política de Anahuak. 